\title{
Vegetation fractional coverage change in a typical oasis region in Tarim River Watershed based on remote sensing
}

\author{
Fei ZHANG ${ }^{1,2 *}$, Tashpolat TIYIP ${ }^{1,2}$, JianLi DING ${ }^{1,2}$, Mamat SAWUT ${ }^{1,2}$, Verner Carl JOHNSON ${ }^{3}$, Nigara \\ TASHPOLAT ${ }^{1,2}$, DongWei GUI ${ }^{4,5}$ \\ ${ }^{1}$ College of Resources and Environment Science, Xinjiang University, Urumqi 830046, China; \\ ${ }^{2}$ Key Laboratory of Oasis Ecology, Xinjiang University, Urumqi 830046, China; \\ ${ }^{3}$ Department of Physical and Environmental Sciences, Colorado Mesa University Grand Junction, Colorado 81501, USA; \\ ${ }^{4}$ Xinjiang Institute of Ecology and Geography, Chinese Academy of Sciences, Urumqi 830011, China; \\ ${ }^{5}$ Cele National Station of Observation \& Research for Desert-Grassland Ecosystem in Xinjiang, Cele 848300, China
}

\begin{abstract}
Vegetation fractional coverage (VFC) is an important index to describe and evaluate the ecological system. The vegetation index is widely used to monitor vegetation coverage in the field of remote sensing (RS). In this paper, the author conducted a case study of the delta oasis of Weigan and Kuqa rivers, which is a typical saline area in the Tarim River Watershed. The current study was based on the TM/ETM+ images of 1989, 2001, and 2006, and supported by Geographic Information System (GIS) spatial analysis, vegetation index, and dimidiate pixel model. In addition, VBSI (vegetation, bare soil and shadow indices) suitable for TM/ETM+ images, constructed with FCD (forest canopy density) model principle and put forward by ITTO (International Tropical Timber Organization), was used, and it was applied to estimate the VFC. The estimation accuracy was later proven to be up to $83.52 \%$. Further, the study analyzed and appraised the changes in vegetation patterns and revealed a pattern of spatial change in the vegetation coverage of the study area by producing the map of VFC levels in the delta oasis. Forest, grassland, and farmland were the three main land-use types with high and extremely-high coverage, and they played an important role in maintaining the vegetation. The forest area determined the changes of the coverage area, whereas the other two land types affected the directions of change. Therefore, planting trees, protecting grasslands, reclaiming farmlands, and controlling unused lands should be included in a long-term program because of their importance in keeping regional vegetation coverage. Finally, the dynamic variation of VFC in the study area was evaluated according to the quantity and spatial distribution rendered by plant cover digital images to deeply analyze the reason behind the variation.
\end{abstract}

Keywords: vegetation fractional coverage (VFC); VBSI (vegetation, bare soil and shadow indices); dimidiate pixel model; delta oasis of Weigan and Kuqa rivers

Citation: Fei ZHANG, Tashpolat TIYIP, JianLi DING, Mamat SAWUT, Verner Carl JOHNSON, Nigara TASHPOLAT, DongWei GUI. 2013. Vegetation fractional coverage change in a typical oasis region in Tarim River Watershed based on remote sensing. Journal of Arid Land, 5(1): 89-101.

Vegetation fractional coverage (VFC) is the vertical projection of vegetation (including leaves, stems, or shoots) to the ground surface and is expressed as the fraction or percentage of the reference area (Purevdorj et al., 1998; Gitelson et al., 2001; Chen and Chen, 2006; Godínez-Alvarez et al., 2009). VFC couples natural environmental changes and human activities, and is an essential index to describe the ecological system (Sellers et al., 1996; Liu et al., 2009). In addition, VFC is a critical variable in global and regional hydrological and climatic model simulations. Vegetation, including forests, bushes, grasslands, farmlands, and orchards, as important components of the ecological cycle, can maintain the ecological environment. Vegetation is the main index used for measuring the state and performance of the ecological environment.

"Corresponding author: Fei ZHANG (E-mail: zhangfei3s@yahoo.com.cn) Received 2012-04-29; revised 2012-06-22; accepted 2012-07-10

(c) Xinjiang Institute of Ecology and Geography, Chinese Academy of Sciences, Science Press and Springer-Verlag Berlin Heidelberg 2013 
Vegetation change attaches a great importance to global energy circulation and geo-biochemical circulation of substances. Therefore, monitoring VFC has a great significance for both ecology and society (Wang et al., 2008; Fan and Zhang, 2009), and VFC estimation of a large area has become a foundation in establishing global and regional climate and hydrological models (Chen et al., 2001). VFC measurement using traditional estimation from field sampling, however, could be really cost- and effort-consuming and could result in low precision due to obvious spatial and temporal variations. In this regard, the new method of VFC estimation includes the experience model and vegetation index conversion technique (Zhang et al., 2003). The former technique relies on the field data in specific areas, and has many limitations in application although it can achieve certain accuracy in small areas. The latter technique, which directly converses vegetation index (VI) to VFC, is becoming a preferred method (Gai et al., 2009).

VI is indirectly obtained by new techniques, such as remote sensing. It is an indirect but comprehensive abstraction and general measurement of the vegetation coverage; thus, the conversion from VI to VFC is necessary (Jiang et al., 2006). Recently, various studies have been conducted on remote sensing monitoring. These studies have boosted the application of numerous measuring methods, such as GIS spatial analysis, VI, regression analysis, artificial neural network (ANN), and dimidiate pixel model (Leprieur et al., 1994; Chen et al., 2001; Zribi et al., 2003; Patel et al., 2007; Xie et al., 2008; Jiapaer et al., 2011). The combination of VI and dimidiate pixel model is widely applied for VFC measurement (Qi et al., 2000; Zhang et al., 2008; Hu et al., 2009; Zhang et al., 2009a; Liu and Ren, 2012; Ma et al., 2012). This combined process is done to collect corresponding image wavebands on the ground of remote sensing images, build a model to obtain VBSI, and finally estimate VFC through VI conversion technique. The VI in the study area has been chosen from International Tropical Timber Organization (ITTO), i.e. Forest Canopy Density Mapping Model (FCD Model) (Rikimaru and Miyatake, 1997). Thus, the VBSI that could weaken the influences came from the shadow and soil background. The current study found that about $90 \%$ of the data in the diagram of vegetation cover based on the TM-based FCD model are accurate compared with field investigation data (Rikimaru, 1996; Li et al., 2003).

The delta oasis of Weigan and Kuqa rivers, dominated by agriculture with farming and herding cultures, is one of the most important production bases for grains and cotton in Xinjiang. Therefore, the paper chose the delta oasis as the study area by studying the TM/ETM+ images of 1989, 2001, and 2006 to calculate the VFC with VBSI. Remote sensing monitoring on the dynamic change of coverage in the oasis was conducted. The paper attempts to offer evidentiary support for ecological construction and sustainable development from the result of the dynamic variation rules in the three periods.

\section{Study area}

The delta oasis of Weigan and Kuqa rivers ("the oasis") is located to the south of Tianshan Mountains and the north of the Tarim Basin, with geographic coordinates between $41^{\circ} 06^{\prime}-41^{\circ} 38^{\prime} \mathrm{N}$ and $81^{\circ} 26^{\prime}-83^{\circ} 17^{\prime} \mathrm{E}$. It is a typical and complete piedmont alluvial-pluvial fan plain, including the Kuqa, Xinhe, and Shaya counties of the Aksu prefecture. In the study area, the underlying surface conditions are basically similar and the topographic relief is not obvious (Fig. 1). Weigan River radiates from the mountain pass, forming a large fan oasis, which is $64 \mathrm{~km}$ long from east to west and $160 \mathrm{~km}$ wide from north to south. The average altitude of the oasis is $920-1,100 \mathrm{~m}$ from south to north. The delta oasis of Weigan and Kuqa rivers covers about $5.35 \times 10^{6} \mathrm{hm}^{2}$. The oasis has a typical continental climate with low precipitation, strong evaporation, large temperature differences, strong wind and windblown sand, and long sunshine hours. The average annual precipitation in the study area is $51.6 \mathrm{~mm}$, with $60 \%$ to $70 \%$ falling between May and August. The average evaporation is $1,992.0$ to $2,863.4 \mathrm{~mm}$ and the annual average temperature is $10.5^{\circ} \mathrm{C}$ to $11.40^{\circ} \mathrm{C}$ (the highest temperature is $41.5^{\circ} \mathrm{C}$ and the lowest is $-28.9^{\circ} \mathrm{C}$ ). The area is dominated by northeast wind and the gales are from the north. The frost-free season of the area falls 


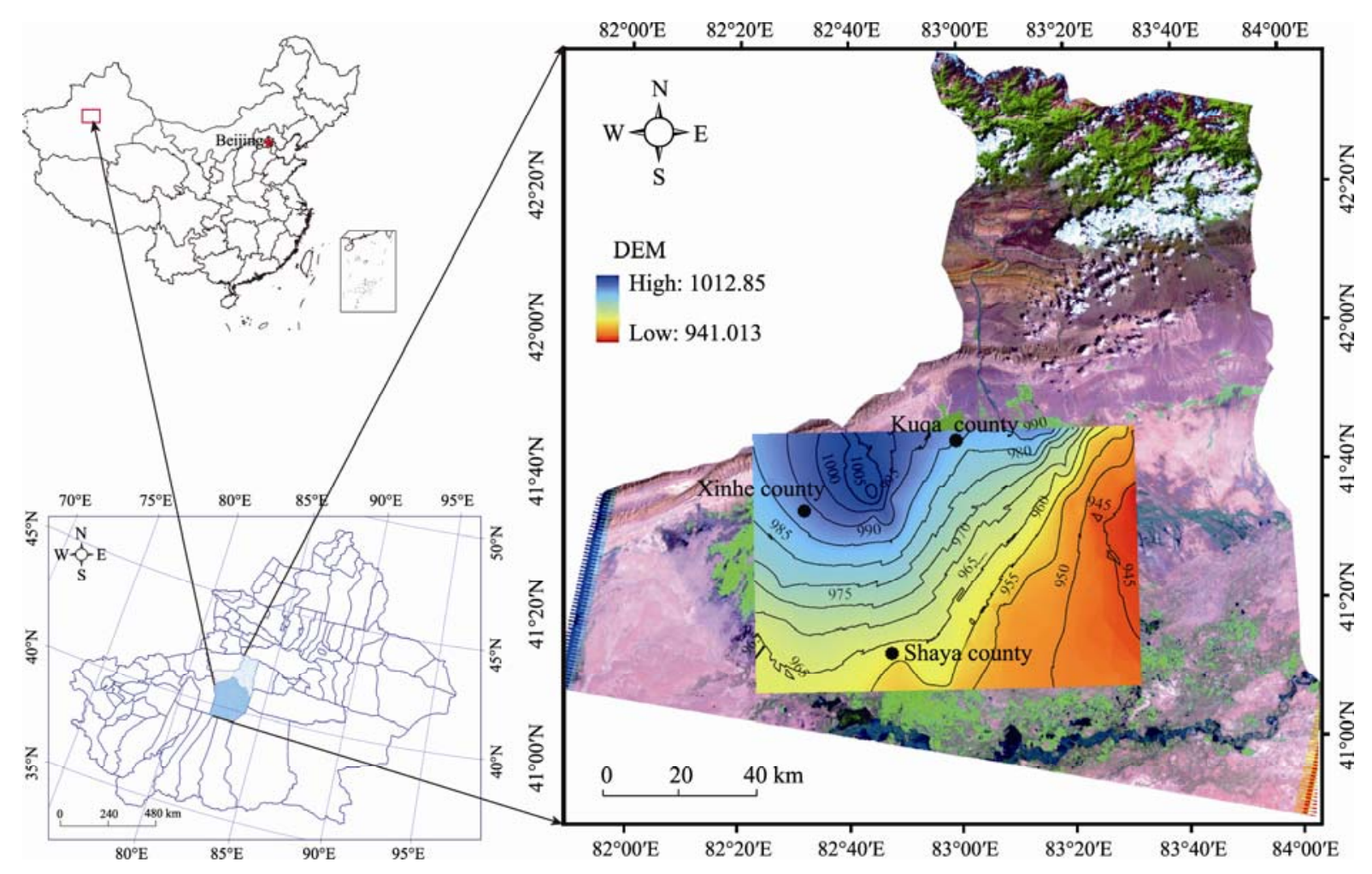

Fig. 1 Map of the study area

between 209.8-226.4 d. In the past, the oasis had abundant water resources. Situation has changed since the 1970s; however, due to the faster development at the upper reaches region, an increased use of water has led to the decrease of water resources in the lower reaches. Gradually, the water courses of the rivers dried up, the desert expanded, and the primary plants degenerated. At present, the oasis is of a typical desert vegetation type and show further degradation (Zhang et al., 2009b; Ma et al., 2011).

The vegetation in the oasis mainly consists of economic crops and natural vegetation. The former includes cotton, corn, winter wheat, and so on, and the latter is mostly covered by halophytic pants widely scattered in the oasis. The coverage and distribution features of the vegetation depend on groundwater level, salt, and the altitude. The plants distributed at the edge of the oasis and on the two sides of the water channel are richer and have a greater coverage. They include succulent halophytes and salt-secreting plants, such as Halostachys caspica, Halocnemum strobilaceum, Alhagi sparsifolia, Nitrarria sibirica, Tamarix ramosissima, Karelinia caspia and Phragmites australis.

\section{Data and methods}

\subsection{Data}

In order to monitor the change of vegetation coverage based on multi-temporal satellite images, the study chose three periods of Landsat TM/ETM+ images (Path 145, Row 31) for 25 September 1989, 1 August 2001, and 22 July 2006. The images were taken when crops and natural vegetations were growing well and could fully represent the growing conditions of the vegetation in the study area. Vegetation in the area usually grows and develops from May to October, and June to September is the best period (Yang et al., 2009). Other data sources in the study include: land use/cover map and vector data of Kuqa, Xinhe and Shaya counties for 1988, 1995 and 2002; statistics data of historical land surveys, populations and social economies; field exploration data and landscape GPS photos. 


\subsubsection{Image geometric correction}

The Landsat TM image acquired on 22 July 2006 was geometrically corrected on the basis of the 1:50,000 digitized raster map. The digitized raster map was set as the base image, and there were about 60 ground control points selected using ENVI 4.8 software. The Landsat TM image was warped using the third-degree polynomial model, and the Landsat TM was linearly re-sampled with a resolution of $30 \mathrm{~m}$. The geometric correction precision was better than half a pixel. The geo-corrected Landsat TM image was set as the base image, and the other two Landsat TM/ETM+ images were then geo-referenced to the Landsat TM image. The geometric correction precision was better than one pixel.

\subsubsection{Image radiometric calibration}

Raw images recorded the digital number (DN). In order to get accurate VBSI results, we transformed the DN value to the reflectivity. After radiation calibration, we could get the image reflectivity. Firstly, the empirical line calibration method was employed for radiometric calibration for the TM image of 22 July 2006, and the TM image was then converted from DN to reflectance. Secondly, the pseudo-invariant objects, such as water, bare soil and dense vegetation, were selected from the three Landsat TM/ETM+ images. Finally, the other two images were matched to the TM image of 22 July 2006, using the least square regression method, and the other two Landsat TM/ETM+ images were converted from DN values to reflectance which was finally used as an input for further analysis (National Aeronautics and Space Administration, 2004).

\subsection{Methods}

\subsubsection{FCD model}

The FCD (forest canopy density) model was proposed based on the biophysical characteristics of the forest, including four main indices, i.e. vegetation index (VI), bare soil index (BI), shadow index (SI), and thermal index (TI, which is rarely used). The features and relations of the four indices are shown in Fig. 2 (Jiang et al., 2005). The features of RS images used in this paper, namely, blue waveband $\left(\mathrm{B}_{1}\right)$, green waveband $\left(B_{2}\right)$, red waveband $\left(B_{3}\right)$, near-infrared waveband $\left(B_{4}\right)$, and short infrared wave band $\left(B_{5}\right)$, were employed to build VI, BI, and SI (Li et al., 2003; Jiang et al., 2005).

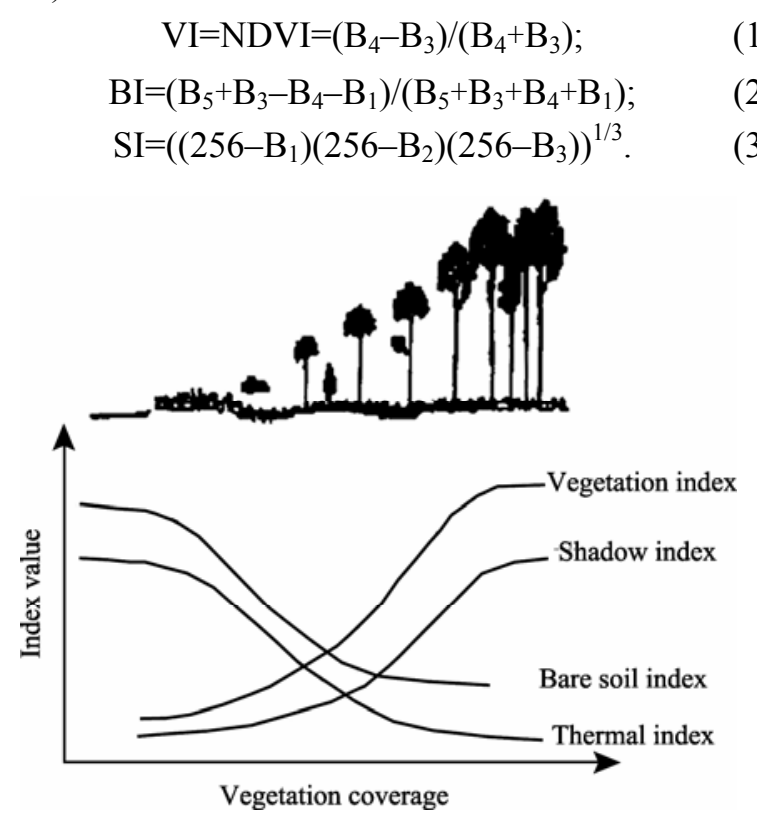

Fig. 2 The principle of FCD model

\subsubsection{Construction of VBSI index}

Studies on VI, BI and SI have shown a positive correlation between SI and VI. A negative correlation between BI and VI was shown (Jiang et al., 2006). The effects from image shadows, soil backgrounds, rocks and building lots could be reduced by linearly combining VI, BI, and SI to some extent. Therefore, VBSI index was constituted on the ground of the test

$$
\mathrm{VBSI}=f(\mathrm{VI}, \mathrm{BI}, \mathrm{SI})=(\mathrm{VI}+\mathrm{n} \times \mathrm{BI}) \times \mathrm{SI} \text {. }
$$

Where $\mathrm{n}$ is the correction coefficient. According to the actual condition and the tests, $\mathrm{n}$ is equal to -0.1 . The VBSI of the whole image was calculated (Fig. 3), and all these operations above were done by employing ENVI remote sensing software.

\subsubsection{Remote sensing estimation model for VFC}

The dimidiate pixel model is a simple but practical model for remote sensing estimation. The model hypothesizes that the 1-pixel surface consists of two parts: the vegetation-covered and the vegetation-uncovered surfaces. The spectral information observed using a remote sensor is also a weighted linear combination of the two component factors. The weight of each factor is the percentage of its size to the pixel, e.g., VFC can be regarded as the weight value of vegetation (Jiang et al., 2006; Qiao et al., 2006). Ac- 

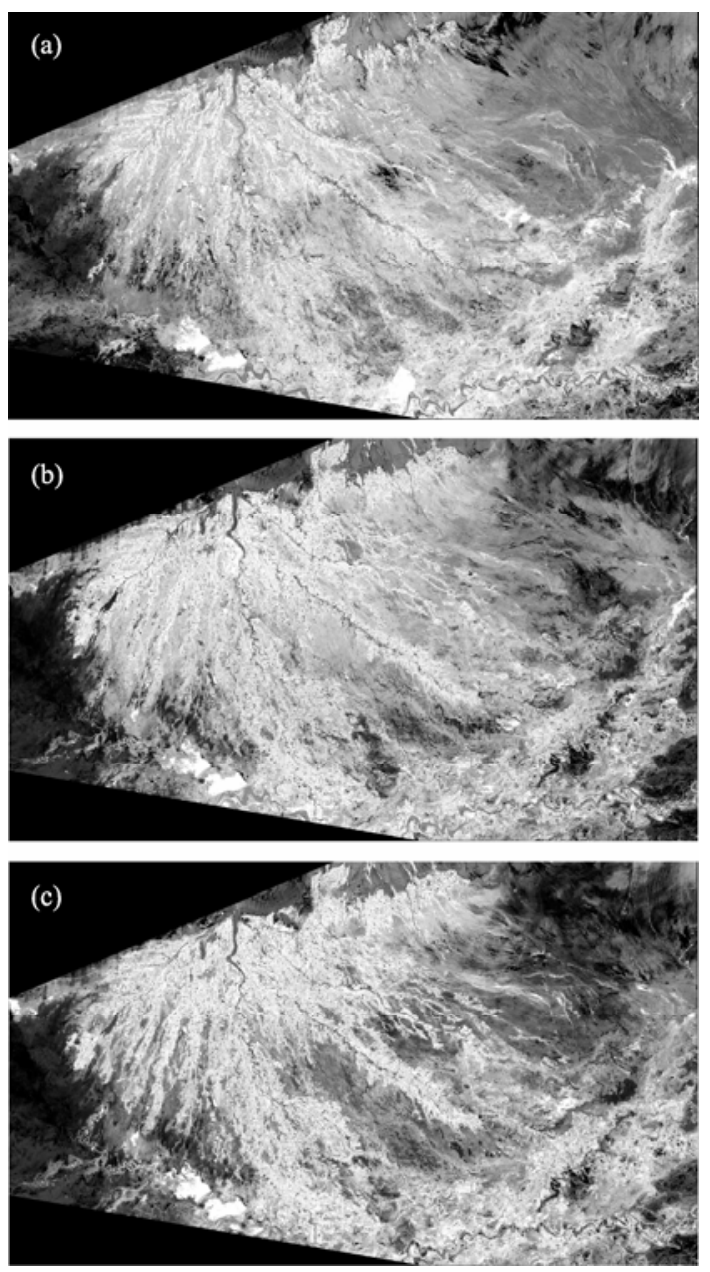

Fig. 3 The VBSI map of the study area in 1989 (a), 2001(b) and 2006 (c)

cording to the principle of dimidiate pixel model $S$, the information observed from the remote sensor can be expressed as the sum of $S_{\mathrm{v}}$, the information contributed by the green vegetation components, and $S_{\mathrm{s}}$, the information coming from the soil components. The mixed pixel model simplifies the pixel information $S$ into $S_{\mathrm{v}}$ and $S_{\mathrm{s}}$, representing the vegetation information and non-vegetation information, respectively.

$$
S=S_{\mathrm{v}}+S_{\mathrm{s}} \text {. }
$$

Let $f_{\mathrm{c}}$ be the coverage percentage of the vegetation in one pixel, i.e., the VFC of this pixel, then the percents of the non-vegetaion coverage is $1-f_{\mathrm{c}}$. If let $S_{\mathrm{veg}}$ be the pixel information under all covered by vegetation, $S_{\mathrm{v}}$ can be expressed as the product of $S_{\mathrm{veg}}$ and $f_{\mathrm{c}}$.

$$
S_{\mathrm{v}}=f_{\mathrm{c}} \times S_{\mathrm{veg}} \text {. }
$$

Similarly, if there is no vegetation coverage (pure pixel all covered by soils) and let $S_{\text {soil }}$ be the pixel information, then $S_{\mathrm{s}}$ is the product of $S_{\text {soil }}$ and $1-f_{\mathrm{c}}$.

$$
S_{\mathrm{s}}=\left(1-f_{\mathrm{c}}\right) \times S_{\text {soil }} .
$$

Substituting Equations 6 and 7 into Equation 5, the following equation can be obtained:

$$
S=f_{\mathrm{c}} \times S_{\text {veg }}+\left(1-f_{\mathrm{c}}\right) \times S_{\text {soil }} \text {. }
$$

Equation 8 can be translated as linearly decomposing $S$ into $S_{\text {veg }}$ and $S_{\text {soil }}$. The weight value of each part is the percentage of its size to the pixel, i.e., $f_{\mathrm{c}}$ and $1-f_{\mathrm{c}}$. Equation 8 shall be corrected for the pixels combining more than two components. This analysis hypothesis is based on one pixel that only has two components: vegetation and soil.

By changing Equation 8, the following expression can be obtained to calculate the VFC:

$$
f_{\mathrm{c}}=\left(S-S_{\text {soil }}\right) /\left(S_{\text {veg }}-S_{\text {soil }}\right) \text {. }
$$

Where both $S_{\text {veg }}$ and $S_{\text {soil }}$ are parameters, so VFC can be calculated based on the RS information by Equation 9. The reduction of the effect from atmosphere, soil background, and vegetation type is considered as one of the advantages of the dimidiate pixel model. RS information is generally influenced by these factors and removing these effects has been an urgent issue tackled by researchers. The dimidiate pixel model introduces $S_{\text {soil }}$ and $S_{\text {veg }}$ to weaken the influences of these effects. $S_{\text {soil }}$ covers all information about the soil, such as type, color, brightness, and humidity, among others. $S_{\text {veg }}$ includes information about vegetation, such as type and structure, among others. $S_{\text {soil }}$ and $S_{\text {veg }}$ are affected by gas and cover the related information for the RS database. The dimidiate pixel model is the linear extension based on $S_{\text {soil }}$ and $S_{\text {veg }}$ to minimize the influences from atmosphere, soil background and vegetation type to RS information and to keep the information regarding VFC (Li et al., 2004; Niu et al., 2005).

\subsubsection{Estimating VFC by VBSI}

VBSI is a composite vegetation index after the linear combination of the object spectral information corrected by the RS sensor. It reflects the quantitative value of the surface vegetation. The technical flowchart is given in Fig. 4. According to the dimidiate pixel model and by substituting VBSI into Equation 8, an approximate value can be obtained:

$$
V B S I=f_{\mathrm{c}} \times V B S I_{\text {veg }}+\left(1-f_{\mathrm{c}}\right) \times V B S I_{\text {soil }} \text {. }
$$

That is, the VBSI value in each pixel can be regarded as the weighted average of the VBSI between areas covered and uncovered with vegetations, of 
which the weighted value of the covered area is the VFC of the pixel, whereas that from the uncovered area is $1-f_{c}$. VBSI soil is the VBSI value of bare soil or non-vegetation area in Equation 10, i.e. the VBSI value of non-vegetaion pixel. $V B S I_{\text {veg }}$ is the VBSI value of the pixel covered by vegetation, i.e. the VBSI value of pure vegetation pixel. By transforming Equation 9, the following expression can be obtained:

$$
f_{c}=\left(V B S I-V B S I_{\text {soil }}\right) /\left(V B S I_{\text {veg }}-V B S I_{\text {soil }}\right) \text {. }
$$

According to the land cover classification, $V B S I_{\text {veg }}$ and $V B S I_{\text {soil }}$ are substituted respectively by the maximum and the minimum cumulative percentage ranging from $0.5 \%$ to $99.5 \%$ ( $\mathrm{Li}$ et al., 2009 ) within the confidence interval to decrease the error and calculate the VFC in 1989, 2001, and 2006.

\subsubsection{Classification of VFC}

According to the Standards for Classification and Gradation of Soil Erosion (The Ministry of Water Resources of the People's Republic of China, 1996) issued by the Ministry of Water Resources and the Technical Rules of Land Use Survey (The Ministry of Land and Resources of the People's Republic of China, 2007) and based on the ecological characteristics of oasis vegetation in arid regions, the VFC of the study area was divided into five levels (Cai et al., 2005), as in Table 1. Figure 5 is photograph of sampling.

\section{Results and discussion}

\subsection{Estimation of results and accuracy of VFC}

The current paper used the band model in ENVI software to directly implement Equation 11 for the calculation of VBSI and VFC. Finally, the raster drawing of the VFC in the oasis was produced (Fig. 6).

The average VFCs in 1989, 2001, and 2006 in the study area are $40.17 \%, 38.9 \%$, and $53.6 \%$, respectively. Considering the small time span of the sampling and the strong practicability, a field survey was conducted to verify the result of the field measured value. In July 2006, GPS and digital camera (for photos taken vertically from the ground) were used to perform field sampling and to obtain the VFC of the sampling objects according to the judgment of experts. Visual estimation is not a stable method to measure the accuracy and credibility of VFC (Zhang et al., $2001 \mathrm{a}, \mathrm{b})$. In practice, we selected 25 sampling points and combined the photographic method with the visual estimation method. Correlated analysis between mixed pixel of VFC results and measurement of VFC results showed that these different methods have high correlation (Fig. 7), and average relative error is $16.48 \%$. Finally, the general accuracy of the method was proven to be $83.52 \%$, which means the dimidiate pixel model based on VBSI can meet the requirement of VFC observation in the study area.

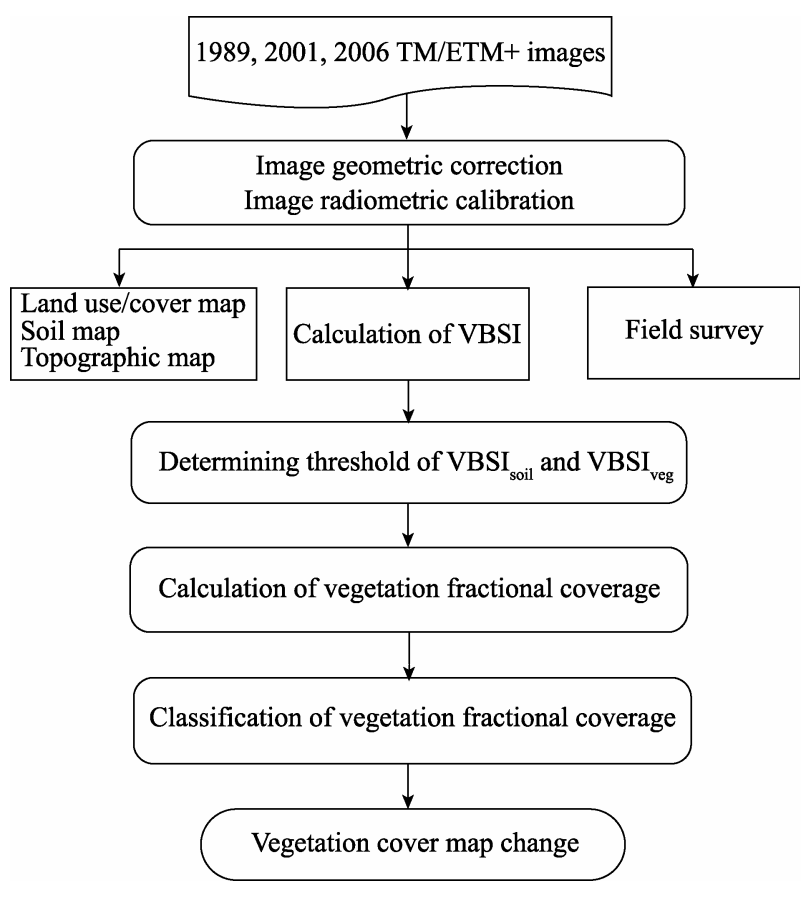

Fig. 4 The technical flowchart of this research

Table 1 VFC grade and description

\begin{tabular}{lll}
\hline VFC grade & \multicolumn{1}{c}{ Type } & \multicolumn{1}{c}{ Description } \\
\hline Level I & Extremely low coverage & $\begin{array}{l}\text { VFC ranging less than } 10 \% \text {; extremely sandy desertified land and bare land } \\
\text { VFC ranging from } 10 \% \text { to } 30 \% \text {; poor vegetation in the low-yield grassland, open forest land, and wasted } \\
\text { land, among others }\end{array}$ \\
Level II & Low coverage & $\begin{array}{l}\text { VFC ranging from } 30 \% \text { to } 50 \% \text {; areas with moderate vegetation, such as moderate-yield grassland and } \\
\text { forestland with low canopy density }\end{array}$ \\
Level III & Moderate coverage & $\begin{array}{l}\text { VFC ranging from } 50 \% \text { to } 70 \% \text {; areas with good vegetation, most of which are beach land, high-yield } \\
\text { grassland, and forestland }\end{array}$ \\
Level IV & High coverage & VFC is more than $70 \%$; such as dense woodland and extremely high-yield grassland \\
\hline
\end{tabular}




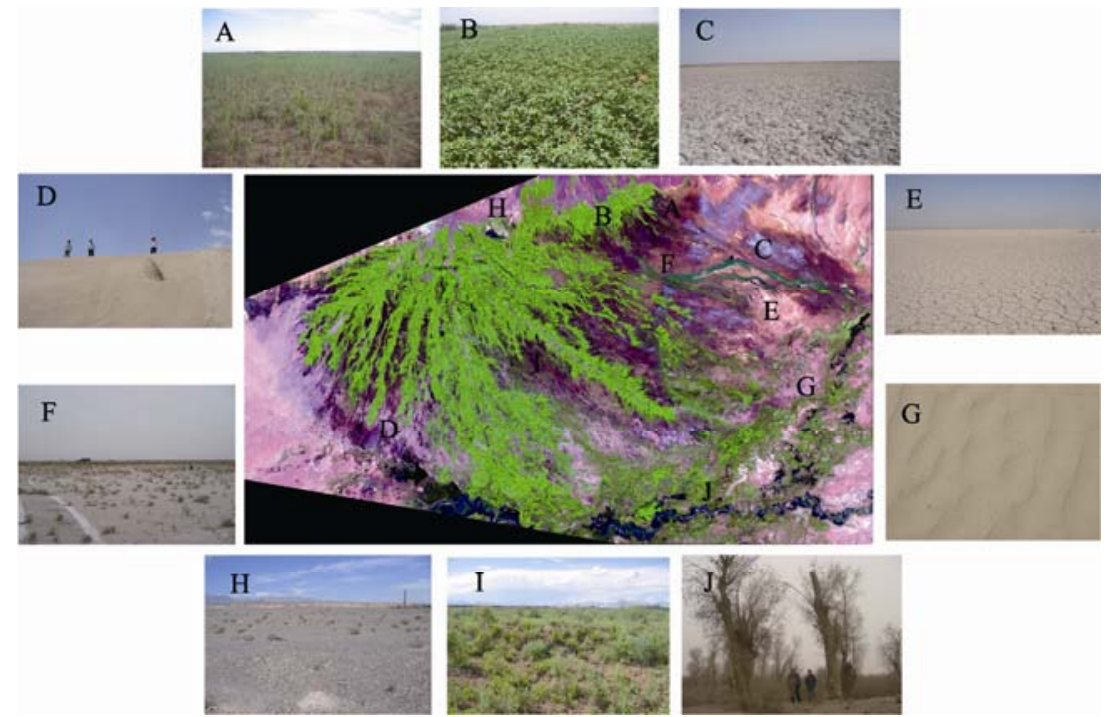

Fig. 5 Photograph of sampling ( $A$ is moderate vegetation coverage; $B$ is extremely high vegetation coverage; C, D, G, E and $H$ are extremely low vegetation coverage; $\mathrm{F}$ is low vegetation coverage; I and $\mathrm{J}$ are high vegetation coverage)
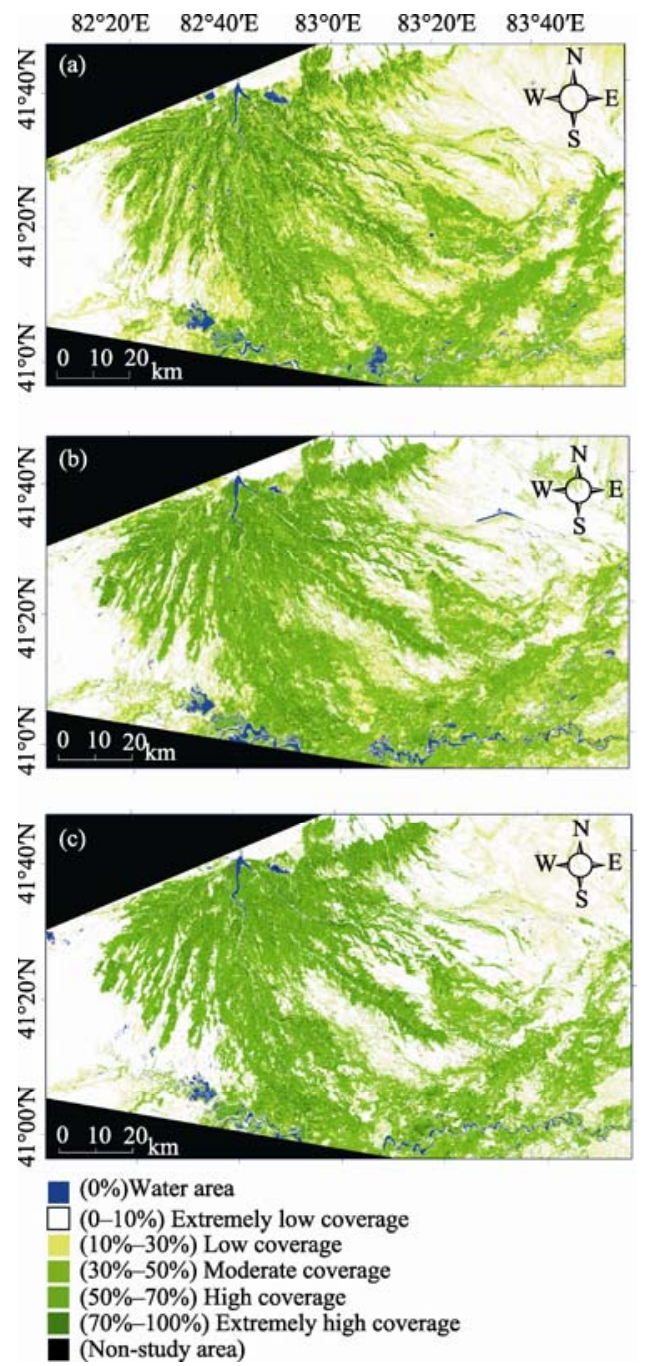

Fig. 6 The vegetation coverage image in Weigan-Kuqa oasis in 1989 (a), 2001(b) and 2006 (c)

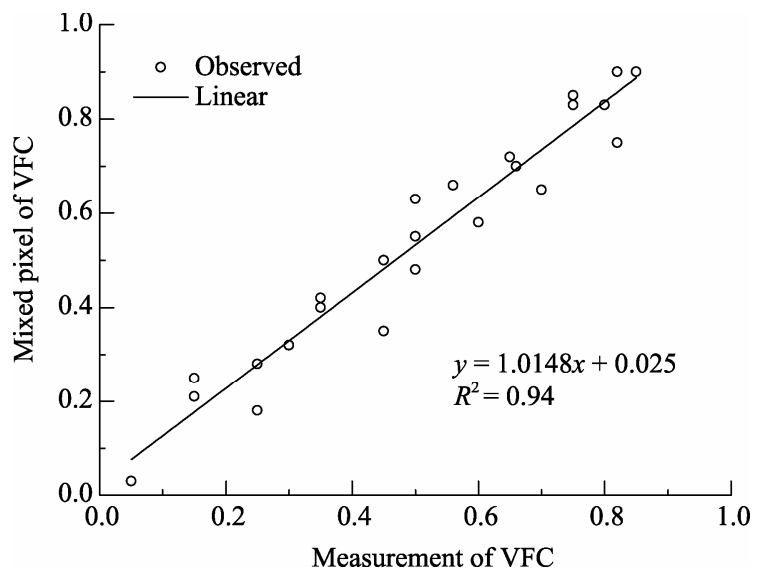

Fig. 7 Correlation analysis between measurement of VFC and mixed pixel of VFC

By classifying the vegetation coverage map using the five VFC types (I-V in Table 2), the areas and changing rates of the levels can be observed (Table 2). The oasis is mostly in levels I and II, accounting for more than $1 / 2$ of the total area. Up to $1 / 3$ of the oasis is in levels III and IV.

In the 1989-2001 period, Level II and III have the lowest and highest average annual change rate of $-0.869 \%$ and $+0.631 \%$, respectively; Level I and IV vary between $+0.42 \%$ and $-0.2 \%$, and Level $\mathrm{V}$ has the least variation for that period. Level I and III areas were $48.736 \times 10^{4}$ and $31.271 \times 10^{4} \mathrm{hm}^{2}$ in 2001 , a slight increase in 1989 when the areas were $42.144 \times 10^{4}$ and $21.371 \times 10^{4} \mathrm{hm}^{2}$, respectively. In the $2001-2006$ period, the highest and the lowest average annual 
Table 2 Change of vegetation coverage of Weigan-Kuqa oasis in 1989, 2001 and 2006

\begin{tabular}{|c|c|c|c|c|c|c|c|c|}
\hline Year & Index & $\begin{array}{l}\text { Water } \\
\text { bodies }\end{array}$ & $\begin{array}{c}\text { Extremely low C } \\
\text { I }\end{array}$ & $\begin{array}{c}\text { Low C } \\
\text { II }\end{array}$ & $\begin{array}{c}\text { Moderate C } \\
\text { III } \\
\end{array}$ & $\begin{array}{c}\text { High C } \\
\text { IV }\end{array}$ & $\begin{array}{c}\text { Extremely high } \mathrm{C} \\
\mathrm{V}\end{array}$ & Total area \\
\hline 1989 & Area $\left(\times 10^{4} \mathrm{hm}^{2}\right)$ & 1.706 & 42.144 & 35.255 & 21.371 & 23.553 & 6.731 & 130.761 \\
\hline 2001 & Area $\left(\times 10^{4} \mathrm{hm}^{2}\right)$ & 2.154 & 48.736 & 21.624 & 31.271 & 20.421 & 6.556 & 130.761 \\
\hline \multirow[t]{2}{*}{2006} & Area $\left(\times 10^{4} \mathrm{hm}^{2}\right)$ & 1.468 & 61.945 & 10.710 & 27.023 & 22.700 & 6.915 & 130.761 \\
\hline & Area change $\left(\times 10^{4} \mathrm{hm}^{2}\right)$ & 0.447 & 6.591 & -13.631 & 9.900 & -3.132 & -0.175 & - \\
\hline \multirow[t]{3}{*}{ 1989-2001 } & Change rate $(\%)$ & 0.342 & 5.041 & -10.425 & 7.571 & -2.395 & -0.134 & - \\
\hline & Average annual change rate $(\%)$ & 0.029 & 0.420 & -0.869 & 0.631 & -0.200 & -0.011 & - \\
\hline & Area change $\left(\times 10^{4} \mathrm{hm}^{2}\right)$ & -0.685 & 13.209 & -10.914 & -4.248 & 2.279 & 0.359 & - \\
\hline \multirow[t]{3}{*}{ 2001-2006 } & Change rate $(\%)$ & -0.524 & 10.102 & -8.347 & -3.249 & 1.743 & 0.275 & 一 \\
\hline & Average annual change rate $(\%)$ & -0.105 & 2.020 & -1.669 & -0.650 & 0.349 & 0.055 & - \\
\hline & Area change $\left(\times 10^{4} \mathrm{hm}^{2}\right)$ & -0.238 & 19.801 & -24.546 & 5.652 & -0.853 & 0.184 & - \\
\hline \multirow[t]{2}{*}{ 1989-2006 } & Change rate $(\%)$ & -0.182 & 15.143 & -18.771 & 4.322 & -0.652 & 0.140 & - \\
\hline & Average annual change rate $(\%)$ & -0.011 & 0.891 & -1.104 & 0.254 & -0.038 & 0.008 & - \\
\hline
\end{tabular}

Note: $\mathrm{C}$ means coverage; change rate $=$ area change/total area; average annual change rate $=$ change rate/ $\mathrm{T}(\mathrm{T}$ indicates monitoring period, e.g. 1989-2001 period; $\mathrm{T}$ is twelve).

change rate are in Level I and II, showing $2.02 \%$ and $-1.669 \%$, respectively; and Level III and IV show $-0.650 \%$ and $0.349 \%$, respectively; Level V exhibited a small change. The areas of Level IV and V exhibit a slight variation, from $20.421 \times 10^{4}$ and $6.556 \times 10^{4} \mathrm{hm}^{2}$ in 2001 to $22.7 \times 10^{4}$ and $6.915 \times 10^{4}$ $\mathrm{hm}^{2}$ in 2006. From 1989-2006, the average annual change rate of Level I and II increase to $0.891 \%$ and decrease to $1.104 \%$, respectively, showing the highest average annual change during the period. The smallest change is with Level V, only $0.008 \%$. Both Level I and III showed an increase in area, from $42.144 \times 10^{4}$ and $21.371 \times 10^{4} \mathrm{hm}^{2}$ in 1989 to $61.945 \times 10^{4}$ and $27.023 \times 10^{4} \mathrm{hm}^{2}$ in 2006 , respectively. The study showed that the condition of global ecological environment is worsening, although the local ecological environment is improving.

\subsection{Analysis of the dynamic change of VFC}

The spatial overlay technique was used to analyze the map of VFC levels in different periods, in order to measure the exact structure and variation of VFC in the study area. Finally, the transfer matrix of the five levels was obtained (Tables 3-5).

Table 3 shows that all diagonal data were from the unchanged levels (excluding water bodies), covering $64.71 \times 10^{4} \mathrm{hm}^{2}$ and occupying $49.5 \%$ of the total area. Extremely low coverage was the main reason behind this condition, followed by low coverage. The degraded vegetation area $(\mathrm{V} \rightarrow \mathrm{IV}, \mathrm{V} \rightarrow \mathrm{III}, \mathrm{V} \rightarrow \mathrm{II}, \mathrm{V} \rightarrow \mathrm{I}$, $\mathrm{IV} \rightarrow \mathrm{III}, \quad \mathrm{IV} \rightarrow \mathrm{II}, \mathrm{IV} \rightarrow \mathrm{I}, \quad \mathrm{III} \rightarrow \mathrm{II}, \mathrm{III} \rightarrow \mathrm{I}, \mathrm{II} \rightarrow \mathrm{I})$ was $27.37 \times 10^{4} \mathrm{hm}^{2}$. The restoration area $(\mathrm{I} \rightarrow \mathrm{II}, \mathrm{I} \rightarrow \mathrm{III}$, $\mathrm{I} \rightarrow \mathrm{IV}, \mathrm{I} \rightarrow \mathrm{V}, \mathrm{II} \rightarrow \mathrm{III}, \mathrm{II} \rightarrow \mathrm{IV}, \mathrm{II} \rightarrow \mathrm{V}, \mathrm{III} \rightarrow \mathrm{IV}, \mathrm{III} \rightarrow \mathrm{V}$, $\mathrm{IV} \rightarrow \mathrm{V}$ ) was $36.02 \times 10^{4} \mathrm{hm}^{2}$, which was about 1.3 times that of the former. The current study has shown that during 1989 and 2001, the vegetation had been in a healthy variation.

Table 4 shows an unchanged area of $72.76 \times 10^{4} \mathrm{hm}^{2}$, which occupied $55.6 \%$ of the total area and was mostly due to extremely low coverage and some moderate coverage. The restoration area was $32.37 \times 10^{4} \mathrm{hm}^{2}$, about 1.4 times that of the $22.90 \times 10^{4} \mathrm{hm}^{2}$ degraded vegetation area, which also showed a healthy change during the period.

Table 3 Transfer matrix of vegetation fractional coverage in Weigan-Kuqa oasis from 1989 to 2001

\begin{tabular}{|c|c|c|c|c|c|c|}
\hline \multirow[b]{2}{*}{2001} & \multicolumn{6}{|c|}{1989} \\
\hline & Water bodies & $\begin{array}{l}\text { Extremely low C } \\
\text { I }\end{array}$ & $\begin{array}{c}\text { Low C } \\
\text { II }\end{array}$ & $\begin{array}{c}\text { Moderate C } \\
\text { III }\end{array}$ & $\begin{array}{l}\text { High C } \\
\text { IV }\end{array}$ & $\begin{array}{c}\text { Extremely high } \mathrm{C} \\
\mathrm{V}\end{array}$ \\
\hline Water bodies & 0.878 & 0.472 & 0.364 & 0.253 & 0.177 & 0.007 \\
\hline Extremely low C I & 0.243 & 34.540 & 11.739 & 1.555 & 0.579 & 0.437 \\
\hline Low C II & 0.228 & 3.965 & 10.572 & 4.734 & 1.936 & 0.173 \\
\hline Moderate C III & 0.277 & 2.316 & 7.899 & 9.477 & 10.173 & 1.114 \\
\hline High C IV & 0.072 & 0.592 & 3.525 & 4.340 & 8.306 & 3.583 \\
\hline Extremely high $\mathrm{C} \mathrm{V}$ & 0.009 & 0.186 & 1.153 & 1.013 & 2.385 & 1.810 \\
\hline
\end{tabular}


Table 4 Transfer matrix of vegetation fractional coverage in Weigan-Kuqa oasis from 2001 to 2006

\begin{tabular}{|c|c|c|c|c|c|c|}
\hline \multirow[b]{2}{*}{2006} & \multicolumn{6}{|c|}{2001} \\
\hline & Water bodies & $\begin{array}{c}\text { Extremely low C } \\
\text { I }\end{array}$ & $\begin{array}{c}\text { Low C } \\
\text { II }\end{array}$ & $\begin{array}{c}\text { Moderate C } \\
\text { III }\end{array}$ & $\begin{array}{c}\text { High C } \\
\text { IV }\end{array}$ & $\begin{array}{c}\text { Extremely high } \mathrm{C} \\
\mathrm{V}\end{array}$ \\
\hline Water bodies & 0.919 & 0.294 & 0.121 & 0.116 & 0.016 & 0.002 \\
\hline Extremely low C I & 0.639 & 42.575 & 12.145 & 5.988 & 0.513 & 0.060 \\
\hline Low C II & 0.160 & 3.204 & 3.203 & 3.620 & 0.446 & 0.065 \\
\hline Moderate C III & 0.329 & 1.984 & 4.551 & 14.032 & 5.200 & 0.927 \\
\hline High C IV & 0.086 & 0.580 & 1.380 & 6.390 & 10.856 & 3.408 \\
\hline Extremely high $\mathrm{C} V$ & 0.012 & 0.083 & 0.216 & 1.121 & 3.389 & 2.094 \\
\hline
\end{tabular}

Table 5 Transfer matrix of vegetation fractional coverage in Weigan-Kuqa oasis from 1989 to 2006

\begin{tabular}{|c|c|c|c|c|c|c|}
\hline \multirow[b]{2}{*}{2006} & \multicolumn{6}{|c|}{1989} \\
\hline & Water bodies & $\begin{array}{c}\text { Extremely low C } \\
\text { I } \\
\end{array}$ & $\begin{array}{c}\text { Low C } \\
\text { II }\end{array}$ & $\begin{array}{c}\text { Moderate C } \\
\text { III } \\
\end{array}$ & $\begin{array}{c}\text { High C } \\
\text { IV }\end{array}$ & $\begin{array}{c}\text { Extremely high } \mathrm{C} \\
\mathrm{V}\end{array}$ \\
\hline Water bodies & 0.692 & 0.330 & 0.234 & 0.148 & 0.063 & 0.001 \\
\hline Extremely low C I & 0.498 & 36.540 & 18.737 & 4.538 & 1.525 & 0.088 \\
\hline Low C II & 0.121 & 2.580 & 3.956 & 2.549 & 1.411 & 0.078 \\
\hline Moderate C III & 0.259 & 1.629 & 6.635 & 7.919 & 9.330 & 1.247 \\
\hline High C IV & 0.112 & 0.851 & 4.352 & 4.936 & 8.653 & 3.795 \\
\hline Extremely high $\mathrm{C} \mathrm{V}$ & 0.016 & 0.191 & 1.336 & 1.281 & 2.569 & 1.523 \\
\hline
\end{tabular}

Table 5 shows that due to extremely low and high coverage, the unchanged area was $58.59 \times 10^{4} \mathrm{hm}^{2}$, covering $44.8 \%$ of the total area. The degraded vegetation area was $26.36 \times 10^{4} \mathrm{hm}^{2}$, whereas the restoration area was $43.30 \times 10^{4} \mathrm{hm}^{2}$, which is approximately 1.6 times higher. This observation means that from 1989 to 2006 , the measures to restore vegetation have been successful.

The spatial and temporal changes of the vegetation and land use and land coverage for the years of 1989, 2001, and 2006 are shown in Fig. 8. The farmland, forest, grassland, and gardens have very similar borderlines in Fig. 8a and the only differences among these land uses are the degrees of fragmentation and evenness and their spatial variations and changes. The predominant desertification (extremely low coverage area) occurs in the northeast and southwest of the Weigan-Kuqa oasis as shown in Fig. 8b for 1989, 2001, and 2006. Fig. 8c shows that the low and moderate coverage are mainly distributed in the ecotone and a small number of them are scattered at the periphery of the oasis for 1989, 2001, and 2006.

\subsection{Driving forces of VFC variation}

After in-depth theoretical studies and field survey, the study argues that the variations of VFC are mainly driven by climate and human factors.
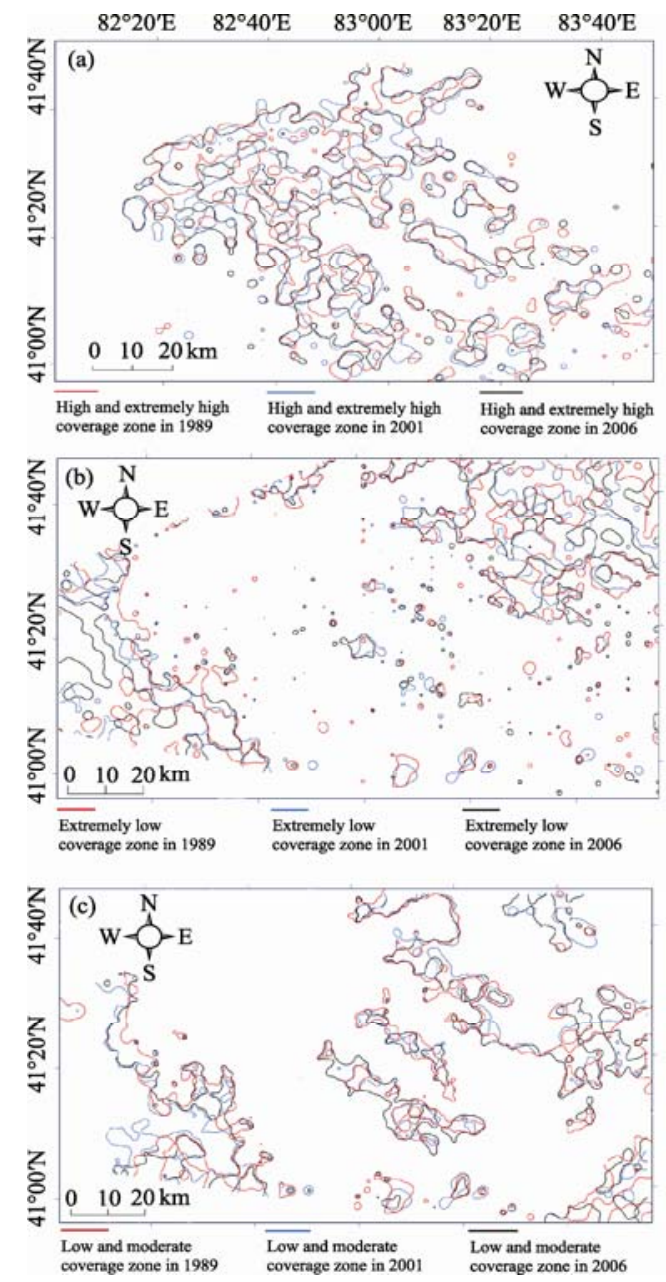

Fig. 8 Extraction borderline of vegetation fractional coverage 


\subsubsection{Climate factor}

The relationship between vegetation coverage variation and climate change at the global scale has been studied by researchers (Yang et al., 2010; Li and Liu, 2012; Liu et al., 2012; Wang et al., 2012). It was found that vegetation index and climatic variables (for example, precipitation, temperature and evaporation) have a good correlation. The climate condition of the study area is shown in Fig. 9. The precipitation in arid and semi-arid regions is a limitation to vegetation growth, and precipitation is essential to the spatial distribution of vegetation. The oasis is located in the south of Tianshan Mountains and the north of the Tarim Basin. The terrain is from south to north, surrounded by desert and gobi, thereby forming an extremely dry environment. Under global climate change, the oasis is becoming warmer and drier, which will intensify soil moisture evaporation and vegetation transpiration in the area. Although the precipitation and evaporation showed a downward trend from 1976 to 2007, the temperature showed an obvious upward trend form 1976 to 2007. Li and Tao (2000) found that the impact of temperature on vegetation exceeds precipitation in most areas of China, causing the runoff of the rivers to increase, such as the annual runoff of Weigan river, which increased from $21.86 \times 10^{8} \mathrm{~m}^{3}$ in 1998 to $24.02 \times 10^{8} \mathrm{~m}^{3}$ in 2008 (Tang et al., 2012 ). All of these could lead to an increase in vegetation coverage to a certain extent.

\subsubsection{Human factor}

In 1989, a total of 0.61 million people lived in the study area, and in 2001, the population was 0.73 million. During the twelve years, the population increased by 0.12 million, with a total growth of $16.44 \%$ and an annual growth rate of $1.37 \%$. In 2006 , the total population of study area was 0.8 million, increased by $8.75 \%$ compared with 2001, and the annual growth rate is $1.75 \%$. Along with the increase of the population, the land utilization has also increased. Compared with natural conditions, human activities is a more dominant factor. Human activities, such as agriculture production and ecological construction, significantly drove the improvement of vegetation coverage. Recently, ecological effects have been achieved due to some large-scale ecological projects, such as natural forest protection, plain greening, grassland improvement, and ecological management of the Tarim River. In addition, driven by economic benefits in the recent years, cotton production has been increasing. Thus,
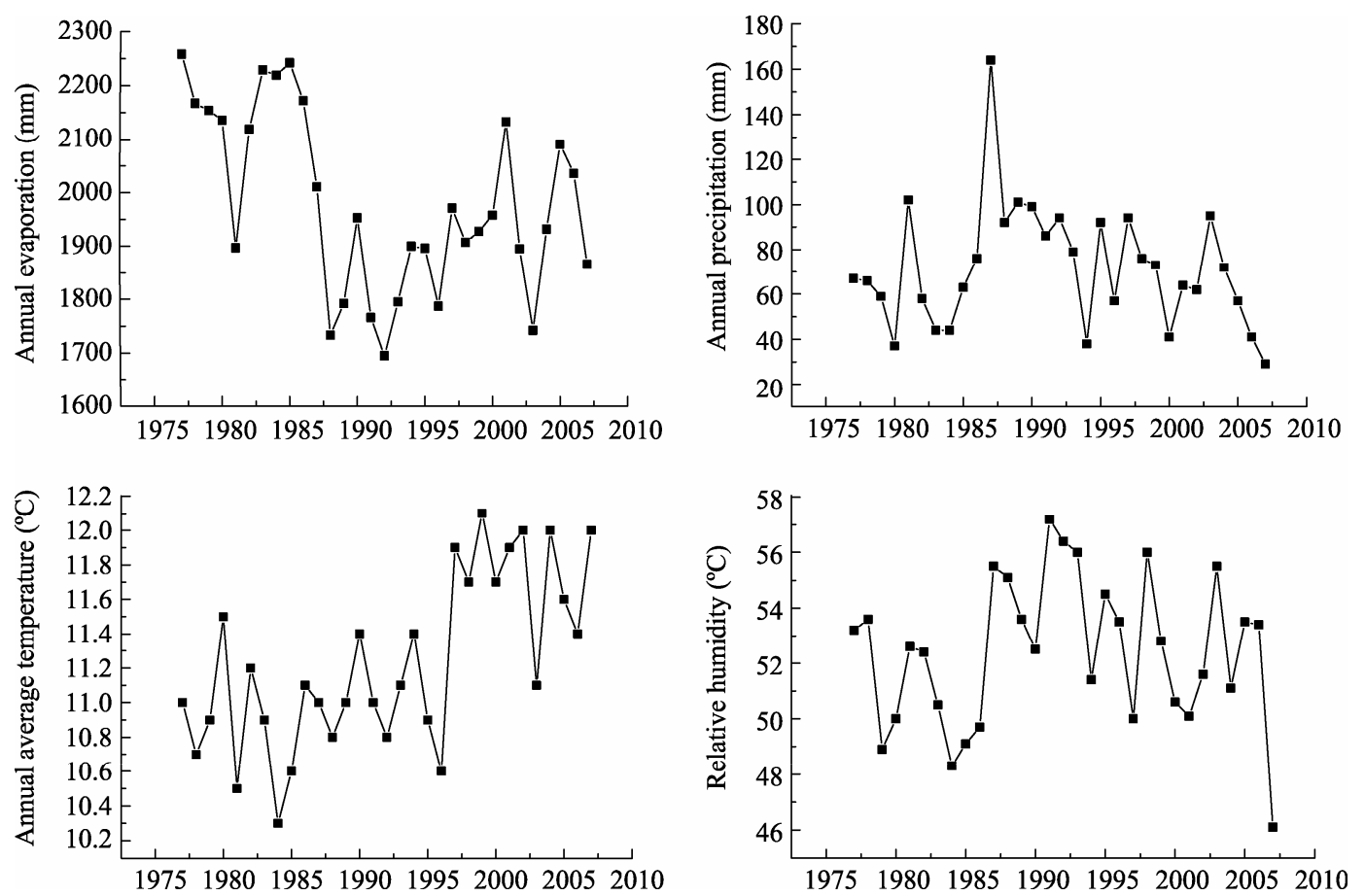

Fig. 9 The temperature, precipitation, evaporation and relative humidity of Weigan-Kuqa river oasis from 1976 to 2007 
some natural oases and wastelands have turned into cotton fields. In 1989, the irrigation area of the oases in Weigan-Kuqa river basin was $11 \times 10^{4} \mathrm{hm}^{2}$, and it increased to $15 \times 10^{4} \mathrm{hm}^{2}$ in 2006 , which slightly increased the vegetation coverage. The extremely high vegetation coverage is closely related to the local government management, i.e. controlling and preventing desertification, and planting trees in the ecotone between oasis and desert, all of which has helped to improve vegetation coverage and the ecological environment.

From the map of VFC levels in 1989, 2001, and 2006 and the analyses above, it was found that the VFC in the study area showed an increasing trend in the 17 years. Level $\mathrm{V}$ area increased because the improvement of the vegetation growth. With the development of social economy, people became increasingly aware of the importance of environmental protection, ecological construction, and sustainable development, and took measures to restore forestland or grassland. Therefore, Levels III and V areas showed slight increases, implying that the ecological projects in the Tarim River Basin have been successful in some areas. However, the increase of level I area was mainly caused by ecological water use.

\section{Conclusions}

After a quantitative research for the 17-year variation of VFC in the delta oasis of Weigan and Kuqa rivers by Landsat TM/ETM+ images in 1989, 2001, and 2006 , and by dynamically analyzing the variation, the paper concludes the following:

1) The methods for calculating VFC based on Landsat TM/ETM+ images, GIS technology, and FCD models can greatly save manpower, physical resources, and time because they do not require large-scale field sampling. The results of the study have shown a general accuracy of $83.52 \%$ of the VFC obtained by mixed pixel method based on the VBSI index. Therefore, the methods can meet the observation requirement of the VFC in the study area, and has a good potential for remote sensing monitoring of VFC.

2) The oasis has shown a big variation in VFC. The average VFC increased from $40.17 \%$ in 1989 to $53.6 \%$ in 2006 mainly due to the increase of tempera- ture, annual runoff, population as well as improved land utilization.

3) The spatial distribution of VFC indicated that the oasis is mostly occupied by level I and II, amounting for more than $1 / 2$ of the total area. Up to $1 / 3$ of the oasis is occupied by level III and IV. From 1989-2006, levels I and II average annual change rates increased to $0.891 \%$ and decreased to $1.104 \%$, respectively, showing the largest average annual change during the period. The smallest change is with level $\mathrm{V}$, with only a variation of $0.008 \%$. Both level I and III showed an increase in area, from $42.144 \times 10^{4}$ and $21.371 \times 10^{4} \mathrm{hm}^{2}$ in 1989 to $61.945 \times 10^{4}$ and $27.023 \times 10^{4} \mathrm{hm}^{2}$ in 2006 , respectively.

4) VFC, an important factor of water and soil loss and landscape patterns, is significant for the protection and sustainable development of the ecological environment. The use of the " $3 \mathrm{~S}$ " method (remote sensing, geography information systems, and global positioning systems) to correctly provide credible data for other studies will be the focus of VFC research in the future.

\section{Acknowledgments}

This study was financially supported by the National Basic Research Program of China (2009CB421302), the Joint Funds of the National Natural Science Foundation of China (U1138303), the National Natural Science Foundation of China (41261090, 41161063), the Open Foundation of State Key Laboratory of Resources and Environment Information Systems (2010KF0003SA), Scientific Research Foundation for Doctor (BS110125), Xinjiang Natural Science Foundation for Young Scholars (2012211B04) and Research Fund for Training Young Teachers (XJEDU2012S03). The authors would like to thank the reviewers for providing helpful comments to improve this manuscript.

\section{References}

Cai T J, Ju C Y, Yao Y F. 2005. Quantitative estimation of vegetation coverage in Mu Us sandy land based on RS and GIS. Chinese Journal of Applied Ecology, 16(12): 2301-2305.

Chen J, Chen Y H, He C Y, et al. 2001. Sub-pixel model for vegetation fraction estimation based on land cover classification. Journal of Remote Sensing, 5(6): 416-423.

Chen Q, Chen Y F. 2006. Monitoring vegetation coverage degree of forestland converted from cropland by applying high resolution sat- 
ellite image. Scientia Silave Sinicae, 42(Suppl.): 5-9.

Fan J L, Zhang X Y. 2009. RS-based analysis on the temporal changes in vegetation in the Ningxia Hui autonomous region in the last 18 years. Arid Zone Research, 26(1): 53-58.

Gai Y Q, Li X B, Zhang L, et al. 2009. Land use/cover change and vegetation coverage monitoring by remote sensing: a case study of Miyun, Beijing. Resources Science, 31(3): 523-529.

Gitelson A A, Kaufman Y J, Stark R, et al. 2001. Novel algorithms for remote estimation of vegetation fraction. Remote Sensing of Environment, 80(1): 76-87.

Godínez-Alvarez H, Herrick J E, Mattocks M, et al. 2009. Comparison of three vegetation monitoring methods: their relative utility for ecological assessment and monitoring. Ecological Indications, 9(5): 1001-1008.

Hu J B, Chen W, Li X Y, et al. 2009. Urban vegetation coverage change inside the Third-Ring Road of Shengyang city, China: a study with linear spectral unmixing technique. Chinese Journal of Applied Ecology, 20(5): 1140-1146.

Jiang H, Wang X Q, Chen X. 2005. A method for abstraction of vegetation density from SPOT image. Geo-information Science, 7(4): 113-116.

Jiang H, Wang Q M, Wang X Q. 2006. Dynamic monitoring of vegetation fraction by remote sensing in Changting county of Fujian province. Journal of Natural Resources, 21(1): 126-132.

Jiapaer G L, Chen X, Bao A M. 2011. A comparison of methods for estimating fractional vegetation cover in arid regions. Agricultural and Forest Meteorology, 151(12): 1698-1710.

Leprieur C, Verstraete M M, Pinty B. 1994. Evaluation of the performance of various vegetation indices to retrieve vegetation cover from AVHRR data. Remote Sensing Reviews, 10(4): 265-284.

Li B G, Tao S. 2000. Correlation between AVHRR NDVI and climate factors. Acta Ecologica Sinica, 20(5): 898-902.

Li H, Lu Z L, Li D Z, et al. 2009. Estimation and monitoring of vegetation coverage dynamics in Chongming county of Shanghai by RS method. Urban Environment \& Urban Ecology, 22(2): 8-11, 15.

Li M M, Wu B F, Yan C Z, et al. 2004. Estimation of vegetation fraction in the upper basin of Miyun Reservoir by remote sensing. Resources Science, 26(4): 153-159.

Li X Q, Sun D F, Zhang F R. 2003. Landscape pattern analysis on change in the fraction of green vegetation based on remotely sensed data in Beijing mountainous area. Journal of Mountain Science, 21(3): 272-280.

Li Y F, Liu G H. 2012. Characteristics of vegetation cover changes in Lantsang Basin based on MODIS vegetation index product (MOD13). Resources Science, 34(7): 1214-1221.

Liu J, Yin S, Zhang G S, et al. 2009. Dynamic change of vegetation coverage of $\mathrm{Mu}$ Us sandland over the 17 years by remote sensing monitor. Journal of Arid Land Resources and Environment, 23(7): $162-167$.

Liu X F, Ren Z Y. 2012. Vegetation coverage change and its relation- ship with climate factors in northwest China. Scientia Agricultura Sinica, 45(10): 1954-1963.

Liu Y A, Huang B, Cheng T, et al. 2012. Vegetation coverage in upper Huaihe River Basin based on binary pixel model of remote sensing. Bulletin of Soil and Water Conservation, 32(1): 93-97.

Ma N, Hu Y F, Zhuang D F, et al. 2012. Vegetation coverage distribution and its changes in plan blue banner based on remote sensing data and dimidiate pixel model. Scientia Geographica Sinica, 32(2): 251-256.

Ma X D, Chen Y N, Zhu C G, et al. 2011. The variation in soil moisture and the appropriate groundwater table for desert riparian forest along the lower Tarim River. Journal of Geographical Sciences, 21(1): 150-162.

National Aeronautics and Space Administration. 2004. Landsat 7 Science Data Users Handbook. USA: National Aeronautics and Space Administration Goddard Space Flight Center. [2009-08-04]. http://ltpwww.gsfc.nasa.gov/IAS/handbook/handbook_htmls/chapte r11/chapter11.html.

Niu B R, Liu J R, Wang Z W. 2005. Remote sensing information extraction based on vegetation fraction in drought and half-drought area. Geomatics and Information Science of Wuhan Universtiy, 30(1): 271-278.

Patel N K, Saxena R K, Shiwalkar A. 2007. Study of fractional vegetation cover using high spectral resolution data. Journal of the Indian Society of Remote Sensing, 35(1): 73-79.

Purvedorj T S, Tateishi R, Ishiyama T. 1998. Relationships between percent vegetation cover and vegetation indices. International Journal of Remote Sensing, 19(18): 3519-3535.

Qi J, Marsett R C, Moran M S, et al. 2000. Spatial and temporal dynamics of vegetation in the San Pedro River Basin area. Agricultural and Forest Meteorology, 105(1): 55-68.

Qiao F, Zhang K B, Zhang S Y. 2006. RS Monitoring on the dynamic change of vegetation coverage in a farming-pasturing ecotone: a case study in Yanchi county, Ningxia Hui autonomous region. Arid Zone Research, 23(2): 283-288.

Rikimaru A. 1996. Landsat TM data processing guide for forest canopy density mapping and monitoring model. Bangkok: ITTO Workshop on Utilization of Remote Sensing in Site Assessment and Planning for Rehabilitation of Logged-over Forest, July 30-August 1, 1-8.

Rikimaru A, Miyatake S. 1997. Development of forest canopy density mapping and monitoring model using indices of vegetation, bare soil and shadow. Colombo: Asian Conference for Remote Sensing. [1997-10-5]. http://www.a-a-r-s.org/acrs/proceeding/ACRS1997/Pa pers/FR97-5.htm.

Sellers P J, Los S O, Tucker C J, et al. 1996. A revised land surface parameterization (SiB2) for atmospheric GCMs. Part II: the generation of global fields of terrestrial biophysical parameters from satellite data. Journal of Climate, 9(4): 706-737.

Tang H, Qiao X N, Yang D G, et al. 2012. Characteristics of temporal and spatial dynamic changes of land use and their relationship with 
regional development: a case study in the Weigan River Basin. Agricultural Research in the Arid Areas, 30(3): 205-213.

The Ministry of Land and Resources of the People's Republic of China. 2007. Technical Regulation for the Second National Land Survey. Beijing: China Standardization Press.

The Ministry of Water Resources of the People's Republic of China. 1996. Standards for Classification and Gradation of Soil Erosion (SL190-96). Beijing: China Water Power Press.

Wang L W, Wei Y X, Niu Z. 2008. Analysis of vegetation spatial and temporal variations in Qinghai Province based on remote sensing. Environmental Science, 29(6): 1754-1760.

Wang X Z, Liang Z X, Zhou X H, et al. 2012. Vegetation coverage and climate change of Maqu county in source region of Yellow River. Research of Soil and Water Conservation, 19(2): 57-65.

Xie X H, Lai R W, Li Y S. 2008. The analysis and appraisal of vegetation coverage pattern in Minjiang Watershed. Journal of Guizhou University: Natural Science, 25(5): 536-539.

Yang G H, Bao A M, Chen X, et al. 2009. Study of the vegetation cover change and its driving factors over Xinjiang during 1998-2007. Journal of Glaciology and Geocryology, 31(3): 436-445.

Yang G H, Bao A M, Chen X, et al. 2010. Vegetation cover change with climate and land use variation along main stream of Tarim River. Journal of Desert Research, 30(6): 1389-1397.
Zhang B Y, Yu Z Z, Liu L Y, et al. 2008. Study on the vegetation coverage changes monitoring of Beijing city by remote sensing. Areal Research and Development, 27(1): 108-112.

Zhang F, Tiyip T, Ding J L, et al. 2009a. Correspondence analysis of relationship between characteristics and spectra of soil salinization. Acta Pedologica Sinica, 46(3): 513-519.

Zhang J X, Liu Z J, Sun X X. 2009b. Changing landscape in the three gorges reservoir area of Yangtze River from 1977 to 2005: land use/land cover, vegetation cover changes estimated using multi-source satellite data. International Journal of Applied Earth Observation and Geoinformation, 11(6): 403-412.

Zhang W B, Liu B Y, Wu J D. 2001a. Monitoring of plant coverage of plots by visual estimation and overhead photograph. Bulletin of Soil and Water Conservation, 21(6): 60-63.

Zhang W B, Fu S H, Liu B Y. 2001b. Error assessment of visual estimation plant coverage. Journal of Beijing Normal University: Natural Science, 37(3): 402-408.

Zhang Y X, Li X B, Chen Y H. 2003. Overview of field and multi-scale remote sensing measurement approaches to grassland vegetation coverage. Advance in Earth Sciences, 18(1): 85-93.

Zribi M, Le Hégarat-Mascle, Taconet O, et al. 2003. Derivation of wild vegetation cover density in semi-arid regions: ERS2/SAR evaluation. International Journal of Remote Sensing, 24(6): 1335-1352. 